\title{
Reforms on the development of the livestock sector and insurance protection in Uzbekistan
}

\author{
Akram Yadgarov ${ }^{1, *}$ and Azizbek Rakhimov ${ }^{1}$ \\ ${ }^{1}$ Tashkent State University of Economics, Uzbekiston Road, 49, Tashkent, Uzbekistan, 100003 \\ ${ }^{2}$ Tashkent State Agrarian University, University str., 2, Tashkent province, Uzbekistan, 100140
}

\begin{abstract}
This article examines the issues of state support for the development of the livestock sector in the country, in particular, subsidies and soft loans, insurance against various diseases and natural disasters, as well as the process of reforms in the field. It also analyzes the current implementation of economic reforms in the development of the livestock sector and provides practical recommendations for the priority development of the sector.
\end{abstract}

\section{Introduction}

Global climate change, the outbreak of various epidemiological diseases directly causes problems such as food security, as well as various natural phenomena (temperature rise, drought, hail, strong winds) that occur during the production of agricultural products (crops, livestock) $[1,10]$. It is no secret that the coronavirus pandemic, which is causing the world economy to go into crisis today, is still on a global scale. Such problems affect the economic stability of many developed countries. One of the global challenges is to provide this population with quality food products $[1,5,9]$. In addition, along with the problems of providing the population with agricultural products through the development of the livestock sector, the issue of insurance protection against various risks in raising the volume of livestock production has risen as one of the urgent tasks [1, 7].

Livestock insurance has been studied by L. Johnson [5] and T. Ye [8] on how to ensure the resilience of livestock farmers to climate change in their households, in particular livestock insurance, insurance against various natural disasters in the production of livestock products. It has also been studied by other scientists such as J. Felix and others [7] for their impact on various unforeseen natural disasters affecting livestock during climate change and drought.

We all know that the livestock sector in Uzbekistan is now one of the most productive. In this regard, one of the important issues in the sustainable development of the livestock sector is to provide the population of the country with livestock products and meet their needs, increase incomes in the livestock sector and create new jobs in this sector. In this regard, insurance protection of the livestock sector from unforeseen natural disasters and natural disasters is one of the most pressing issues.

\footnotetext{
* Corresponding author: a.a.yadgarov@gmail.com
} 
In Uzbekistan, it is aimed at keeping records of livestock, dehkan (individual personnel) farms and households engaged in animal husbandry, feeding, planting and cultivating fodder crops, and fodder storage, ration feeding, artificial insemination and breeding. The breed, origin, exterior and constitution of livestock, productivity, breeding, product identification, certification, and feed preparation technologies, theoretical and practical bases of network development are analyzed [5, 6, 11-13].

Ensuring the effective implementation of these regulations adopted for the development of the livestock sector in Uzbekistan requires the urgency of insurance protection of the livestock sector, which can also affect the supply of food to the population. The research problem is to analyze the development processes of the livestock sector and to study the importance of ongoing reforms in the insurance of the sector in the development of the sector.

The need to implement consistent reforms to support the development of the livestock sector in addressing this research problem is reflected in the following:

- Development of proposals and recommendations for the sustainable development of the livestock sector based on the study of the specifics of its development;

- Assessment of the current situation of farmers and dehkan farms on the basis of the study of problems in the field of livestock production;

- Development of practical recommendations based on the study and analysis of the current implementation of reforms in the insurance of the livestock sector;

- Improving the system of insurance services to support the development of the livestock sector.

In Uzbekistan, as in all sectors, great attention is paid to the development of the livestock sector. In particular, as a result of measures to increase the number of livestock in personal assistants, farmers and farms, economic incentives for the livestock sector, subsidies for the development of the sector, preferential lending to the sector, the organization of a wide range of services and various insurance services access is provided.

\section{Materials and methods}

Today, animal husbandry is one of the main sectors of the agriculture, and it is necessary to develop the meat and dairy industry and the processing industry as a leading sector in the supply of leather and other raw materials.

As a result of increasing global risks and the impact of climate change, drought and similar natural disasters in agriculture, the productivity of agricultural enterprises, especially the livestock sector, is declining. In particular, increasing the volume of livestock production by agricultural enterprises, especially farms and dehkan farms, has been identified as a topical issue today.

There are problems with food security in various countries around the world, in particular, declining food stocks and food shortages. Prices for wheat, rice and corn, which are the main sources of food security on a global scale, as well as meat and dairy products, are rising, and price volatility poses a threat to the population.

The Government is carrying out effective reforms to develop the livestock sector of the agricultural sector and increase the volume of products grown by this sector. As a result of reforms in the livestock sector, the increase in the number of livestock is mainly due to the share of private farms [2-4].

In order to develop the livestock sector in the regions of the country and to import pedigree livestock from foreign countries, benefits are being created for farms. However, issues such as the effective organization and development of specialized farms in the livestock sector have not been adequately addressed. 
Therefore, in this research, we used governmental official data on livestock husbandry sector of Uzbekistan from 2015 to 2020, i.e. implementation of Presidential Decrees and Resolutions, activities of livestock farms, and official statistical data on this economic sector. This helps to gain a better insight into the current state of livestock husbandry in the country [2-4].

\section{Results and discussion}

According to the analysis, in January-December 2020, the total volume of agricultural, forestry and fishery products (services) amounted to 260.3 trillion UZS, including agriculture and livestock, hunting and services in these areas - 251.8 trillion UZS, forestry 6.7 trillion UZS, and fisheries - 1.8 trillion UZS.

As a result of reforms in the agricultural sector in January-December 2020, a positive growth of the livestock sector was achieved, and compared to the same period in 2019 , meat (live weight) increased by $102.1 \%$, milk - by $102.8 \%$.

If we look at the volume of livestock production in 2020 by economic categories, $5.1 \%$ are farms, 3.5\% are agricultural organizations, and 91.4\% are dehkan farms (Figure 1). In January-December 2020, the share of livestock products in the total volume of agricultural production in the agricultural sector amounted to $50.5 \%$.

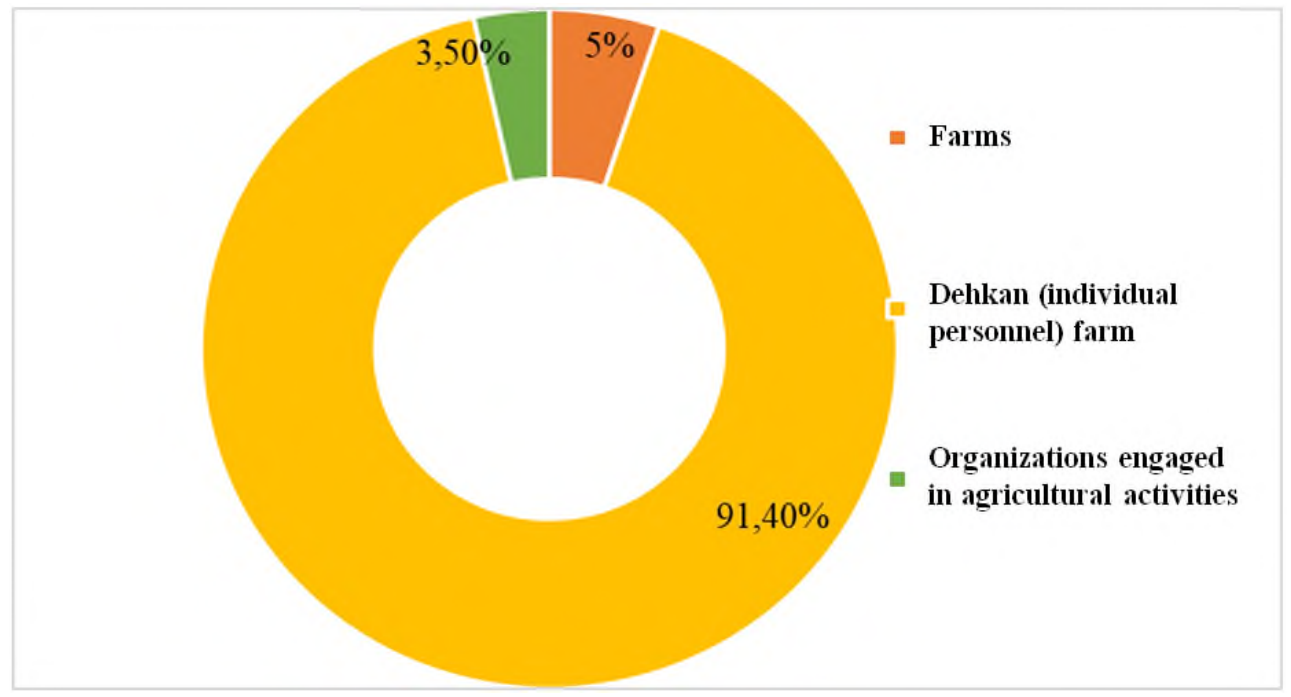

Fig. 1. Distribution of livestock production by economic categories in 2020

The implementation of reforms in Uzbekistan to further increase the domestic capacity of the livestock sector in the agricultural sector, as well as the provision of systematic state support, creates ample opportunities to increase the number of livestock and fill the domestic consumer market with livestock products.

In January-December 2020, all categories of farms produced 2,526.2 thousand tons of meat in live weight (2.1\% more than in January-December 2019), 11,009.9 thousand tons of milk (2.8\% more), 7,825.0 million eggs (an increase of $0.7 \%), 35.7$ thousand tons of wool (an increase of 1.5\%) and 144,085 tons of fish (an increase of 18.4\%) were caught.

Today, the main attention in the development of agricultural enterprises of the country is focused on farms. Also, the development of the livestock sector in farms specializing in animal husbandry has become a requirement of the times. One of the urgent issues is the 
establishment of farms specializing in animal husbandry in all regions of the country and the allocation of soft loans and subsidies to them, the provision of preferences for customs duties on the purchase of breeding livestock.

In this regard, in the development of livestock in the regions, it is necessary to properly plan measures to expand the fodder base for them, increase the number of livestock and increase the supply and demand of the population by creating a value chain, as well as increasing income through price stability.

In accordance with the Resolution of the Cabinet of Ministers of the Republic of Uzbekistan "On the order of insurance of livestock kept in households and businesses" dated September 30, 2019 No 830, the regional branches of "Uzagrosugurta" JSC and other insurance companies were established. Insured livestock also includes families of cattle, sheep, goats, horses, camels, pigs, poultry, fish, fur animals and bees, which are mainly owned by legal entities and individuals.

The insurance coverage of the livestock sector depends mainly on the type of livestock, based on the insured risks: fire, storm, hurricane, flood, earthquake, and freezing as a result of severe cold, poisoning, traffic accidents, explosion, avalanche, wildlife attack, theft, forced slaughter and other cases.

"Uzagrosugurta" JSC provides insurance services in the country to insure livestock against natural disasters and various diseases. In addition, 272,298.7 thousand UZS of insurance premiums were collected in 2015 on the basis of existing livestock insurance contracts in dehkan farms, and 437,75.6 thousand UZS of insurance indemnities were paid to cover the damage. According to the results of 2019, the volume of insurance premiums amounted to $294,272.7$ thousand UZS, while the volume of paid insurance coverage amounted to 53,830.0 thousand UZS (Figure 2).

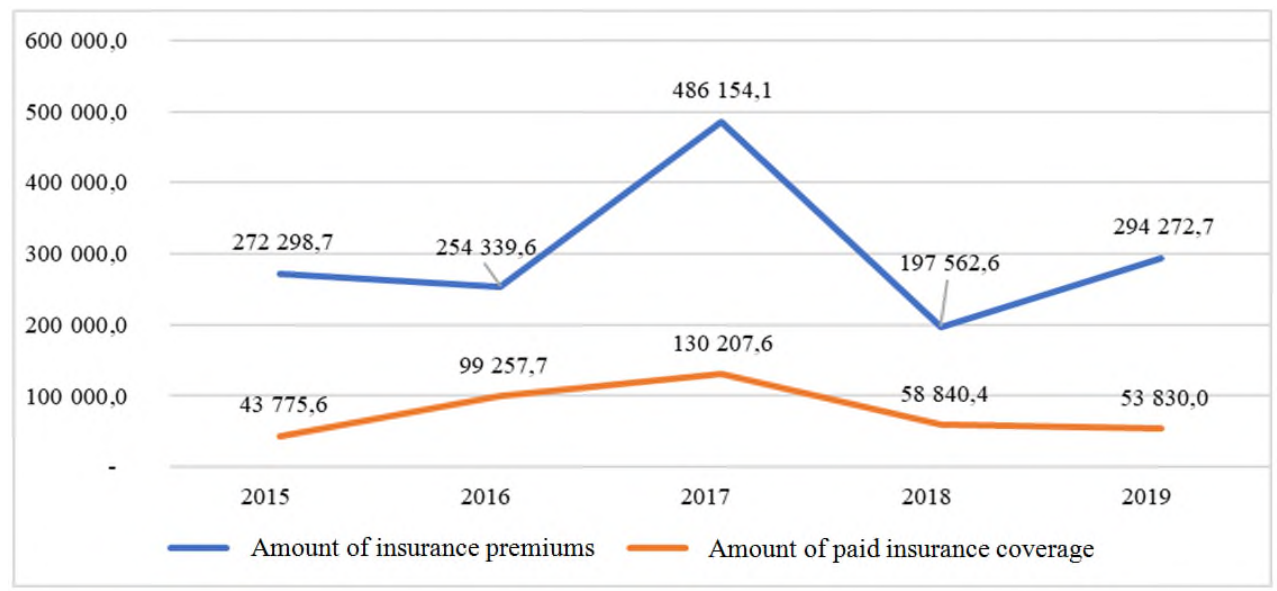

Fig. 2. Status of livestock insurance on dehkan (private) farms

Also, today the role of farms in food supply is growing, along with dehkan farms. The share of farms in the production of livestock products also has a special place, and intensive work is being done to insure livestock belonging to farms.

Analyzing the situation with livestock insurance on farms, in 2015, 28,246.5 thousand UZS of insurance premiums were collected, and 9600.0 thousand UZS of insurance indemnities were paid to cover the losses. According to the results of 2019, the amount of insurance premiums amounted to 2,900.0 thousand UZS, but this year the insurance coverage was not paid due to the absence of an insured event for livestock (Figure 3). 


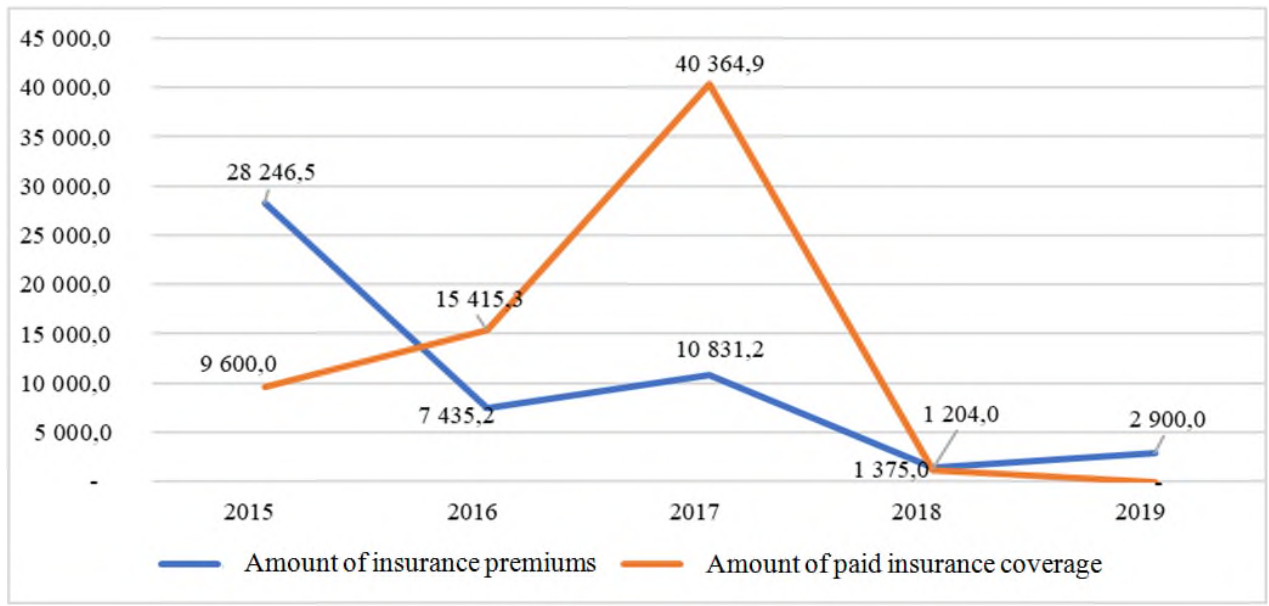

Fig. 3. Status of livestock insurance on farms

In the development of the livestock sector, firstly, to improve economic relations between agriculture and its service enterprises, secondly, to ensure the overall sustainable economic development of the livestock sector through the development of insurance protection system, thirdly, effective use of insurance services in the development of the livestock sector, becoming economic support in finding solutions to such issues.

\section{Conclusion}

The following recommendations should be made to address the above issues:

- Development of promising projects for the development of the livestock sector to ensure food security;

- Development of specialization of farms for the development of the livestock sector based on the location of their territories;

- Ensuring the safety of the livestock sector in agriculture on the basis of permanent insurance;

- It is necessary to radically improve the system of legal protection of agricultural producers and the provision of quality insurance services to them.

In conclusion, it can be said that the development of the livestock sector provides an important basis for ensuring food security through the provision and promotion of bonus insurance services to businesses.

\section{References}

1. T. Gebrekidan, Y. Guo, S. Bi, J. Wang, C. Zhang, J. Wang, K. Lyu, Climate Risk Management 23, 67-77 (2019)

2. Presidential Decree No. 5853 of the Republic of Uzbekistan on "Strategy of agricultural development of the Republic of Uzbekistan for 2020-2030" on October 23 (2019)

3. Presidential Resolution No. 4576 of the Republic of Uzbekistan on "Additional measures of governmental support of the livestock sector" on January 29 (2019)

4. Presidential Resolution No. 5696 of the Republic of Uzbekistan on "Additional measures of governmental support of the livestock sector" on March 28 (2019) 
5. L. Johnson, B. Wandera, N. Jensen, R. Banerjee, The Journal of Development Studies 55(6), 1221-1239 (2019)

6. T. Biglari, H. Maleksaeidi, F. Eskandari, M. Jalali, Land Use Policy 87, 104043 (2019)

7. F. Johna, R. Toth, K. Frank, J. Goeneveld, B. Moeller, Ecological Economics 157, 357-368 (2019)

8. T. Ye, Y. Li, Y. Gao, J. Wang, M. Yi, International journal of disaster risk reduction 23, 160-168 (2017)

9. A. Yadgarov, Economics and Innovative Technologies 2(2020), 147-154 (2020)

10. A. Singh, P. Kumar, H. Kumar, A. Neeraj, P. Kumar, G. Kour, International Journal of Livestock Research 10(5), 8-19 (2020)

11. A. Yadgarov, International Journal of Advanced Science and Technology 29(7), 22512258 (2020)

12. A. Yadgarov, Journal on Banking \& Insurance Research 9, 31-37 (2020)

13. A. Yadgarov, The American Journal of Agriculture and Biomedical Engineering 2(5), 43-52 (2020) 